\title{
The Level Of Possession Of The Students At The Hashemite University Of Professional And Family Counseling Skills In Light Of Achievement And Gender Variables
}

Bassam H.M. ALharbi, Hashemite University, Jordan

Fatin Mhaidat, Hashemite University, Jordan

\begin{abstract}
The present study aimed to identify the level of owning a field training students majoring in psychological counseling at the Hashemite University of professional and family counseling skills in light of achievement and gender variables. The subjects of the study comprised of (100) subjects of field training students in the second semester of the academic year 2014-2015. A questionnaire was used in this study to identify the professional counseling skills and another questionnaire for family counseling skills. Results of the study have shown that field training students majoring in psychological counseling at the Hashemite University own professional and family counseling skills moderately. The results also indicated that the level of students' possession of the professional and family counseling skills rises as GPA rises and that females are more equipped to those skills, compared with males.
\end{abstract}

Keywords: Professional Counseling; Family Counseling; Field Training Students

\section{INTRODUCTION}

\section{Professional Counseling}

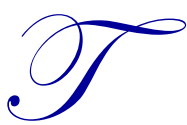

he Career Guidance is considered as one of the most important services and psychological and educational programs that are available in most countries of the world to help the individual to discover his aptitudes and abilities and inclinations to develop himself and his ambitions to enter a profession commensurate with those capabilities and tendencies and to be able to succeed through overcoming these problems (Sheikh Hmoud, 2014).

The vocational counseling is considered the basis for the development of counseling specialization in its different domains, guidance appeared in its beginnings professionally to help individuals choose an appropriate career or a suitable specialization and that was related to Frank Parsons who put three steps for the process of vocational counseling as it is still reliable until this moment (Abu Eita, 2013).

Frank Parsons in his book (Choosing A Vocation) summed the three steps in the study of the individual and the knowledge of his abilities and aptitudes and inclinations as well as the professions' analysis and the required capabilities and preparations, conditions and qualifications, and is the last step in the alignment between them to achieve professional compatibility required, which leads to the success and stability of the professions (Abu Hammad, 2008; Gysbers, Heppner \& Johnston, 2003).

And professional counseling plays a significant role in an individual's personality in his life for present and future, and it is a crucial, and decisive process determines his future and outlines a success or failure, happiness or misery, 
work or unemployment, and professional counseling also achieve many of the economic, social and psychological benefits. Economically, putting the right person in the right place leads to increase his efficiency and the potential for promotion and increased wages and the high level and stability in his work and not being forced to change his career after spending a long time, although the organization may spend a lot of money for his training and education but socially the appropriate choice of individuals to occupy different professions leads to accuracy and perfection and skill at work. Psychologically, the individual's choice of a career that likes and fits his abilities and inclinations make him feel satisfied and happy and achieve success and thus achieve job satisfaction, which will be reflected in his mental and physical health (Abdul Hadi \& Izza, 2012).

Professions field is of a great importance for the individual and society since the profession is considered for an individual a way to serve himself and others, and thus, a sense of the individual in front of himself as a person with the value of being able to benefit those around him, the appreciation of oneself is largely due to the appreciation of others around him, and professions are a way to earn a living, a field in which it expresses the individual's abilities and inclinations and aptitudes and talents; so if putting the individual in a situation that doesn't fit his work cause a loss of emotional balance and lack of job satisfaction, the profession is the end that ends the dream of every young person to become a member of society independent from his (Liang, 2005).

Vocational guidance is a process to help the individual take the accurate decision of the academic selection and then the profession appropriate to his preparations and his abilities and inclinations, and prepare and join it, in order to increase the likelihood of success, progress and development in the field of work, and achieve a state of professional compatibility, meaning that the role of vocational counseling is to help the individual to choose a profession most favorable to him (Jay, 2004).

Super (1990) defines the profession counseling as a process to help the individual in the development and acceptance of an integrated and adequate image of himself and his role in the world of work as well as to help him to test this image in the real world to bring him happiness and benefit to the community.

Polls in the United States indicate that there is an urgent need for professional guidance at all levels and stages of education; every stage of education needs different ways of guidance commensurate with the goals of that stage, and (Zunker, 1998) points to the objectives of these stages as follows:

Primary Stage: career counseling programs are designed to increase awareness and knowledge of students of different professional roles, and the role of work in the community, social behavior and responsible behavior.

Intermediate Stage: career counseling programs are designed to help students to form concepts of basic skills, learn decision-making skills, and learn about the world of work and Psychological affiliation to him.

Secondary Stage: career counseling programs are designed to keep introducing the students in the professions and identify professional alternatives to get ready to enter the world of work or scientific specialization at the university to prepare for a certain profession.

Undergraduate Stage: career counseling programs are designed to help students to establish professional choices and to develop specific and specialized professional skills and to re-evaluate their orientation and their preparations and planning for entry in a particular professional field.

Professional counseling skills are considered very important to improve and develop school students' training to choose suitable profession for their abilities and inclinations and aptitudes and these skills were indicated in some studies such as (Egner \& Jackson 1978) and the study of (Bergland, Quatrano, \& Lundquist, 1975) in addition to the study of (McCollins, 1983) to effectively teach students decision-making to improve planning for the future of their careers. As the study of (Abu Latifa, 2005) also indicates the importance of developing the skill of thinking among school students to improve the ability to choose by teaching thinking skills and career decision-making. 


\section{Family Counseling}

There is no clear definition of family counseling; however, the general characteristics show that it cares about the problems caused by an imbalance in the family system (Horne \& Ohlsen 1982).

Family counseling differs from individual counseling in the treatment of certain disorders among some individuals who did not benefit from individual therapy (Goldenberg \& Goldenberg, 2005).

The Family is considered the cornerstone for building communities, and so the strong family contributes to the formation of a perfect individual who constitutes the basic unit of society, while the weak family contributes to the emergence of unrest among its members Kafafy (2009).

The family consists of father, mother, and children, and sometimes it may have some relatives, and everyone in the family receives the material and moral support from other individuals (Rashdan, 2005).

The disorder of family relationships leads to a lot of problems, such as marital disputes, the constant quarreling, and the emergence of a lot of conflicts between siblings in addition to the abuse of children by parents to prevail turmoil among members of the family as a whole. These disorders in the family also lead to provide inappropriate models of behavior for children, and using violence to crack difficulties and inappropriate methods in the socialization of children. All this may eventually lead to the disintegration of the family either through divorce or the absence of one parent (Horne \& Ohlsen (1982).

The need for family counseling emerged from the conviction that most of the life problems appear through the family, and can be handled within the family because family relationships can be a source of support for each member, it can also be a source of stress and suffering.

Family Counseling may treat many problems and disorders in individuals who did not benefit from individual therapy better than individual counseling (Goldenberg \& Goldenberg, 2005).

According to a study by (Gladding, 2003) concerning the effectiveness of family counseling, the results showed that the diverse forms of family counseling were more effective compared with the absence of treatment and there are no adverse effects of any therapeutic intervention in the family. The family counseling and skills used in it has positive results in dealing with multiple disorders such as addiction of alcohol and drugs, and with depression, stress, obesity, aggressive behavior, and distracting attention. The study of (Bakkar, 2006) contributed to an improvement among mothers in increasing social efficiency by training them on skills to communicate with their children.

The results of the study of) Doherty \& Simmons (1996) that (97\%) of those who were counseled were satisfied with family counseling services provided to them, especially in helping them by counselors in dealing effectively with their problems.

\section{THE STUDY PROBLEM}

The current study problem is to investigate the level of the possession of a field training students majoring in psychological counseling at the Hashemite University of vocational skills and family counseling in light of the achievement and gender variables.

\section{Questions of the Study}

The study seeks to answer the following questions:

1. What is the level of possession a field training students majoring in psychological counseling of vocational counseling skills?

2. What is the level of possession a field training students majoring in psychological counseling of family counseling skills? 
3. Does the level of possession of field training students majoring in psychological counseling of the vocational counseling skills and family counseling due to the grade point average of the student?

4. Does the level of possession of field training students majoring in psychological counseling of the vocational counseling skills and family counseling due to the gender of the student?

\section{Significance of the Study}

The importance of the current study emerged from knowing the level of possession of field training students of vocational and family counseling skills as this will impact on the ability to carry out the requirements of the profession of counseling. The importance of the study stems from knowing whether the GPA and gender variables impact on the level of possession of those skills.

But in practice, the results of this study could provide those who work on psychological counseling program in the Department of Educational Psychology with feedback about the efficacy of substances that the department offers to provide students with the skills they need to do their professional roles in the future to the fullest.

\section{METHODOLOGY AND PROCEDURES:}

\section{The Study Population and its Sample}

The population of the study consisted of field training students majoring in psychological counseling at the Hashemite University for the second semester of the academic year 2014 - 2015. The study sample included all members of the population totaling (100) students.

Table 1. Subjects distributed according to the variables of the study.

\begin{tabular}{|c|c|c|c|}
\hline Variable & Level & Number of students & Percentage \\
\hline \multirow{4}{*}{ Achievement } & Excellent & 11 & $11 \%$ \\
\hline & Very good & 23 & $23 \%$ \\
\hline & Good & 52 & $52 \%$ \\
\hline & Fair & 14 & $14 \%$ \\
\hline \multirow{2}{*}{ Gender } & Male & 20 & $20 \%$ \\
\hline & Female & 80 & $80 \%$ \\
\hline
\end{tabular}

\section{Study Tool}

The researchers have developed a scale to identify vocational counseling skills and another scale for family counseling to determine the level of those skills among field training students majoring in psychological counseling at the Hashemite University according to the cumulative grade point average and gender variables.

\section{Scale of Vocational Counseling}

The scale consisted of (19) items including various counseling skills which the school counselor is supposed to do in the field of vocational counseling. And it adopted the quintet Rank, all paragraphs were positive and give the following values: Agree strongly $=5$, Agree $=4$, unbiased $=3$, disagree $=2$, and strongly disagree $=1$. The degree can range from 19-95 degrees reflect the level of possession of the skills of vocational counseling, the higher the score screened, it means having the skills of vocational counseling in a high degree.

\section{Scale Validity}

To verify the validity of the scale the researcher followed the following:

Content Validity: To verify the content validity of the scale the items of the scale (10) were displayed on arbitrators from the faculty members in the Department of Educational Psychology at the Hashemite University to show their 
opinions about the items of the scale in terms of the integrity and clarity of the language, and the ability to measure the possession of professional counseling skills, and all items have been agreed upon by $80 \%$ of the arbitrators.

Construct Validity: The scale construct validity has been verified where the correlation coefficients were calculated using the Pearson correlation coefficient between the items of the scale and the scale as a whole where the correlation coefficients ranged between (0.459-0.733).

\section{Reliability of the Scale \\ Internal Consistency (Cronbach's Alpha)}

The reliability of the vocational counseling scale was extracted for students of field training using Cronbach's alpha coefficient, where this parameter depends on measuring the internal consistency of the paragraphs of the questionnaire for its ability to give consistent results for the responses of the respondents to the questionnaire items, and it reached the value of $(0.87)$.

\section{Family Counseling Scale}

The scale consisted of (15) items include various counseling skills where the school counselor is supposed to master in the field of family counseling. The quintet rank was adopted, all the items are positive and give the following values: Agree strongly $=5$, agree $=4$, unbiased $=3$, disagree $=2$, and strongly disagree $=1$. The respondents' degree can range from 15-75 degrees that reflect the level of possession of skills in family counseling, and whenever the degree rose, it means possession of those skills is high.

\section{The Validity of the Scale}

To verify the scale validity the researcher did the following:

Content Validity: To verify the content validity of the scale the items of the scale were displayed to (10) arbitrators from the faculty members in the Department of Educational Psychology at the Hashemite University to express their views in the items of the scale in terms of the integrity and clarity of the language, and the ability to measure the possession of family counseling skills, and all the items have been agreed upon by $80 \%$ of the arbitrators.

Construct Validity: The scale construct validity has been verified where the correlation coefficients were calculated using the Pearson correlation coefficient between the paragraphs of the scale and the scale as a whole where the correlation coefficients ranged between $(0.558-0.728)$.

\section{THE SCALE RELIABILITY}

\section{Internal Consistency (Cronbach's Alpha)}

The reliability of the scale of family counseling for students of field training using Cronbach's alpha coefficient, where this parameter depends on measuring the internal consistency of the paragraphs of the questionnaire for its ability to give consistent results for the responses of the respondents to the questionnaire items, and it reached the value of (0923).

\section{Procedures of the Study}

After extracting the validity and reliability semantics of the study tool, the researchers implemented the application procedures, where they distributed the tools to the study sample during class situations, where the researchers submitted themselves to the students and clarified the purpose of the study and its significance and instructions to answer the study tools. 


\section{Study Design}

This is a descriptive study and includes the following variables:

Independent variables include

- Gender: (Male Female)

- Academic Achievement: (excellent, very good, good, acceptable).

Dependent variables include

- Professional counseling skills

- Family counseling skills

\section{Statistical Analysis}

To analyze the data relevant to the study questions the following statistical methods have been used:

- Finding the arithmetic means and standard deviations for each paragraph of the vocational counseling scale.

- Using (Chi-Square) test to determine the differences in the level of possession of a professional and family counseling skills in the study sample depending on the level of independent variables.

\section{RESULTS}

The following are the results of the study, according to its questions:

The present study aimed to identify the level of possession a field training students of vocational counseling and family counseling skills in light of the grade point average and gender variables.

\section{Results Related to the First Question}

What is the level of possession a field training students majoring in psychological counseling of vocational counseling skills?

To answer this question, means and standard deviations of the responses of field training students on each paragraph of vocational counseling skills. Table 2 shows this.

Table 2. Means and standard deviations of the responses of field training students on each paragraph of vocational counseling skills

\begin{tabular}{l|c|c|c}
\hline $\begin{array}{l}\text { The level of possession of field training students of } \\
\text { psychological counseling skills in general }\end{array}$ & 3.64 & Standard deviation & Level \\
\hline
\end{tabular}

The results showed that the level of possession of the field training students of the vocational counseling skills was (3.64) and a standard deviation of (0.562), the degree of possession of students of the skills of vocational counseling is considered medium where the researcher divided the categories of scale as follows: from ( 1 to 2.33 low), (2.34 to 3.67), medium (3.68 to 5) high. The number of paragraphs of a medium level (11) out of (19) paragraphs. With a percentage amounted to $58 \%$.

The highest mean was (4.03) with a high degree of the paragraph which states, "I can use technical means to obtain information on the status of professions and their requirements." Where the least mean of the paragraphs was (3.26), the paragraph which states: "I have no information about the unemployment rate and the needs of the labor market, " with a medium degree. 


\section{Results Related to the Second Question}

What is the level of possession a field training students majoring in psychological counseling of family counseling skills?

In oeder to answer this question, means and standard deviations of the responses of field training students on each paragraph of family counseling skills have been extracted. And Table 3 shows that.

Table 3. Means and standard deviations of the responses of field training students on each paragraph of family counseling skills

\begin{tabular}{l|c|c|c}
\hline $\begin{array}{l}\text { The level of possession of field training students of } \\
\text { family counseling skills in general }\end{array}$ & 3.53 & 0.562 & Level \\
\hline
\end{tabular}

The results showed the level of possession of field training students of family counseling skills was (3.53) and a standard deviation of (0.562), which is medium where the researcher divided the categories of scale as follows: from (1 to 2.33 low), (2 0.34 to 3.67), medium (3.68 to 5) high. The results showed that most of the respondents' answers about the arithmetic mean, which shows a medium level, where the number of paragraphs of a medium level was (7) paragraphs (out of 15 ), with a percentage of $47 \%$. And that the largest mean was (4.12) with a high degree of paragraph which states: "I know a lot of the styles and trends of the erroneous education" followed by the paragraph "I have a knowledge of, and information about domestic violence and its causes" the mean was (3.93). The least mean of the paragraphs was (2.91), a medium degree for the paragraph which states "I have the skill of analysis and representation of the family tree for three generations," preceded by a paragraph: "I have the capacity to apply the domestic valuation techniques" with a mean of (3.09).

\section{Results Related to the Third Question}

Does the level of possession of field training students majoring in psychological counseling of the vocational counseling skills and family counseling due to the grade point average of the student?

In order to answer this question, means and standard deviations of the responses of field training students on each paragraph of career counseling and family counseling skills was extracted. And Table 4 shows that.

Table 4. Shows the means and standard deviations for the responses of field training students on each paragraph of career counseling and family counseling skills

\begin{tabular}{l|l|r|r|r|r}
\hline & & \multicolumn{2}{|c|}{ Profession counseling } & \multicolumn{2}{c}{ Family counseling } \\
& & Mean & Standard deviation & Mean & Standard deviation \\
\hline \multirow{4}{*}{ Cumulative average } & Excellent & 3.57 & 1.047 & 3.67 & .952 \\
\cline { 2 - 6 } & Very good & 3.38 & .988 & 3.14 & .985 \\
\cline { 2 - 6 } & Good & 3.12 & .962 & 2.98 & .925 \\
\cline { 2 - 6 } & Fair & 2.67 & 1.166 & 2.41 & .962 \\
\hline
\end{tabular}

The results indicated that there is a direct correlation between grade point average for students and the level of possessing the professional and family counseling skills. Where the greater the cumulative average rose for the student increased the mean of the paragraphs of the scales the study.

\section{Results Related to the Fourth Question}

Does the level of possession of field training students majoring in psychological counseling of the vocational counseling skills and family counseling due to the gender of the student?

In order to answer this question, means and standard deviations of the responses of field training students on each paragraph of career counseling and family counseling skills was extracted. Shown in Table 5. 
Table 5. Means and standard deviations of the responses of field training students on each paragraph of career counseling and family counseling skills

\begin{tabular}{l|c|c|c|c}
\hline & \multicolumn{2}{c|}{ Profession counseling } & \multicolumn{2}{c}{ Family counseling } \\
\hline Gender & Mean & Standard deviation & Mean & Standard deviation \\
\hline Male & 1.94 & .896 & 2.10 & .868 \\
\hline Female & 3.65 & .945 & 3.54 & .901 \\
\hline
\end{tabular}

The results indicated that females are most equipped to vocational and family counseling skills, compared with males.

\section{DISCUSSION OF THE RESULTS}

\section{Discussion Of The Results Relating To The First Question}

What is the level of possession a field training students majoring in psychological counseling of vocational counseling skills?

Results of the study showed that most of the respondents' answers were around the mean, which indicates its medium, where the number of paragraphs of the medium level was (11) paragraphs out of (19) paragraphs, with a percentage of $58 \%$. This result may be attributed to the presence of several courses on vocational counseling in the specialty of Psychological Counseling studied by field training students, including vocational counseling and counseling and rehabilitative principles of counseling and school counseling where all these materials related to vocational counseling. In addition to the training of students in the schools on this side, vocational counseling takes a lot of space in the plan of field training.

The results also showed that the largest mean was (4.03) with a high degree of the paragraph which states, "I can use technical means to obtain information on the status of professions and their requirements." This result shows the importance of the use of computers in vocational counseling; it plays a role in storing professional information, organizing it and refers to it when needed, and help especially small ones to provide a tremendous amount of professional information on employment opportunities and requirements, as well as follow-up. All you can see developments in the field of computers. This result is due to the availability of those instruments and tools in the hands of students (cellular devices or a laptop or Tablet PCs) and ease of access to the search engines. (Zunker, 2002).

\section{Discussion of the Results Relating to the Second Question}

What is the level of possession a field training students majoring in psychological counseling of family counseling skills?

The results showed that most of the respondents' answers about the mean, which shows a medium level, where the number of paragraphs of the medium level was (7) paragraphs out of (15) paragraphs with a percentage of $47 \%$. This result is due to the study of students of counseling skills guidance and replicated in the courses of psychological counseling plan and that most of these paragraphs included general skills in family counseling away from the depth or specialization such as paragraphs that talk about family counseling. The results also showed that the largest mean reached $(4,12)$ with a high degree of the paragraph which states: "I know a lot about the erroneous styles and trends of Education." This result can be explained by that mistaken upbringing methods is one of the multi-abuse and family problems, children and adolescents and negative behaviors methods they have, and this is what field training students in schools have noticed. Also, methods of socialization and its impact on children taught in most psychological counseling materials studied by students in this specialty material such as child and adolescent mental health problems and rehabilitative counseling. A substance that specializes in specialization plan in the abuse and violence of children that focuses on what violence, abuse and their causes and methods of prevention and treatment strategies. In addition to training students through this course to deal with one or more case, that was exposed to abuse or violence. It appeared also from the results of the study that the least mean of the paragraphs was (2.91), a medium degree for paragraph which states "possessed the skill of analysis and representation of the family tree for 
three generations," preceded by a paragraph: "I have the capacity to apply the domestic valuation techniques" with a mean of $(3,09)$. This explains that this skill is one of the specialized techniques of family therapy between generations which helps the family to draw a representation of the family tree, and put the family on a series of questions to understand through which the family installed the emotional and the prevailing atmosphere in and help it to understand the dynamics skills inside it (Gladding, 2002). Field training material also did not address this aspect of the counseling because of the sensitivity of the Jordanian society about the family relations and the possibility of asking the family for counseling issues.

\section{Discussion of the Results Relating to the Third Question}

Does the level of possession of field training students majoring in psychological counseling of the vocational counseling skills and family counseling due to the grade point average of the student?

The results indicated that there is a direct correlation between grade point average for students and the level of possession of the skills of vocational and family counseling. Where the greater the grade point average for the student rose, the mean of the paragraphs of the study scales increased. This result is consistent with the study of (Herbert \& Alexander, 1997) which showed that there is a positive relationship between the academic- ego and achievement and school performance.

The study of (Herbert \& Alexander, 1998) which showed that there is a positive relationship between academic egoconcept and grade the students through their usage of sports levels and the positive relationship in the acquisition of English language skills.

This result can be explained by that students with high GPA are characterized by seriousness and diligence in the collection of knowledge than the fact that they have a knowledge stocks after studying counseling courses in general and vocational courses in the family counseling, in particular, which helps to increase the possession of those skills. The high achievement is usually associated with a degree of intelligence among students; smart students are the best acquire, absorb and learn the skills that are offered to them.

\section{Discussion of the Results Related to the Fourth Question}

Does the level of possession of field training students majoring in psychological counseling of the vocational counseling skills and family counseling due to the gender of the student?

The results indicated that females are most equipped to the skills of vocational and family counseling, compared with males. This result agrees with the results of studies conducted in several countries, including Jordan, Saudi Arabia and included nearly one million students and showed that females surpassed males from the age of kindergarten to university, because they good listening skills and paying attention and completing homework and good organization

The results of the current study is also consistent with the study of (Martin, Seligman, Angela), which revealed that girls are more self-control, making them better able to understand the test instructions, and that when they were at the confusion between duty and entertainment they follow the call of duty, while males prefer entertainment than the performance of duty. This result can be explained by that females characterized by perseverance and seriousness and discipline.

\section{AUTHOR BIOGRAPHIES}

Bassam H.M. ALharbi holds a Ph.D in Psychological Counseling from the University of Jordan. He is a full-time Lecturer at The Hashemite University since 2014.

Fatin Mhaidat holds a Ph.D in Psychology and Educational Counseling from the University of Jordan. She is an instructor of Educational Sciences at the Hashemite University since 2014. 


\section{REFERENCES}

Abdul Hadi, J. \& Izza, S. (2012) Professional counseling and its theories. House of Culture Amman, Jordan. Abu Eita, S. (2013) Vocational guidance and growth. Dar Al Ahlia Amman, Jordan.

Abu Hammad, N. (2000) Psychological counseling and vocational guidance. Jadara for World Book Amman, Jordan.

Abu Latifa, L. (2005) The impact of a proposed program to develop the skill of the priorities thinking among the ninth grade students to develop the skill of decision-making. (Unpublished $\mathrm{PhD}$ dissertation). University of Jordan, Amman, Jordan.

Bakkar, B. (2006) The impact of a counseling program to train mothers on communication skills in the embodiment of social selfefficacy and the level of their interaction with children. (Unpublished doctoral dissertation). University of Jordan, Amman, Jordan.

Bergland, B., Quatrano, L. \& Lundquist, G. (1978) Group social Models and structured interaction in teaching decision making. Vocational Guidance-Quarterly, 24(1),28-36

Doherty, W. \& Simmons, D. (1996) Clinical practice patterns of Marriage and Family therapists: a national survey of therapists and their clients. Journal of Marital and Family Therapy, 22 ,9-25

Egner, J. \& Jackson, P. (1978) Effectiveness of counseling intervention program for teaching career decision-making skills. Journal of Canceling Psychology, 25, 45-52

Gladding, S. (2002) Family therapy: History, theory and practice. Merrill prentice Hall, $3^{\text {rd }}$ edition, New Jersey.

Gladding, S. (2003) Family therapy: History, theory and practice. Prentice Hall, New Jersey.

Goldenberg, I., \& Goldenberg, H. (2005) Family therapy: An over view ( $7^{\text {th }}$ edition). Monterey, CA: Brooks $\backslash$ solemii.

Gysbers, N., Heppner, M. \& Johnston, J. (2003) Career Counseling: process, Issues, and Techniques, (2th edition), United States of America: Pearson Education, Inc.

Herbert, W. \& Alexander, S. (1997) Causal effects of academic self-concept on academic achievement: Structural equation models of longitudinal data. Journal of Educational Psychology, 89, University of Western Sydney, Australia.

Herbert, W. \& Alexander, S. (1998) Longitudinal Structural Equation Models of Academic Self-Concept and Achievement: Gender Differences in the Development of Math and English Constructs. American Educational Research Journal, 35(4), 705. University of Western Sydney, Australia.

Horne, A. \& Ohlsen, M. (1982) Family counseling and therapy. Itasca, IL: F.E. Peacock.

Jay, C. (2004) Over view of career development theories. Retrieved from http $\backslash$ www.Careerstandards.com\documents $\backslash$ pedagogy $\backslash$ careertheoryoverview.pdf.

Kafafy, A. (2009) Family psychology. $1^{\text {st }}$ edition, Dar Al Fikr Al Arabi, Amman, Jordan.

Liang, S. (2005) Individual's Perception of Career Development and Job Bum out Among Flight Attendants in Taiwan. International Journal of Aviation Psychology, 15(1), 119-134.

McCollins, R. (1983) A study of Effectiveness of a comprehensive career Education program in secondary school (Eighth and Tenth Grade student). Dissertation Abstract International, 168-519, A.P. 198.

Rashdan, A. (2005) Education and socializing. $1^{\text {st }}$ edition, Dar Wael for publication, Amman, Jordan.

Sheikh Hmoud, M. (2014) Professional counseling origins, significance, techniques, theories and global experiences. Dar Al Maseera for publication and distribution, Amman, Jordan.

Super, D. (1990) A Life-span, Life-space approach to career development, In D Brown \&L. Brooks Career choice development Applying Contemporary Theories To Practice, 197-261. San Francisco: Jossey -Bass.

Zunker, G. (1998) Career counseling. (6 $\left.6^{\text {th }} E d\right)$, California, Brooks $\backslash$ Cole publishing company.

Zunker, G. (2002) Career counseling: applied concepts of life planning. (4 $4^{\text {th }}$ ed.) Pacific grove, California: Brooks $\backslash$ Cole publishing company. Retrieved from http:// arabic.arabianbusiness.com 